This article can be cited before page numbers have been issued, to do this please use: C. M. Young, J. E. Taylor and A. D. Smith, Org. Biomol. Chem., 2019, DOI: 10.1039/C9OB00703B.

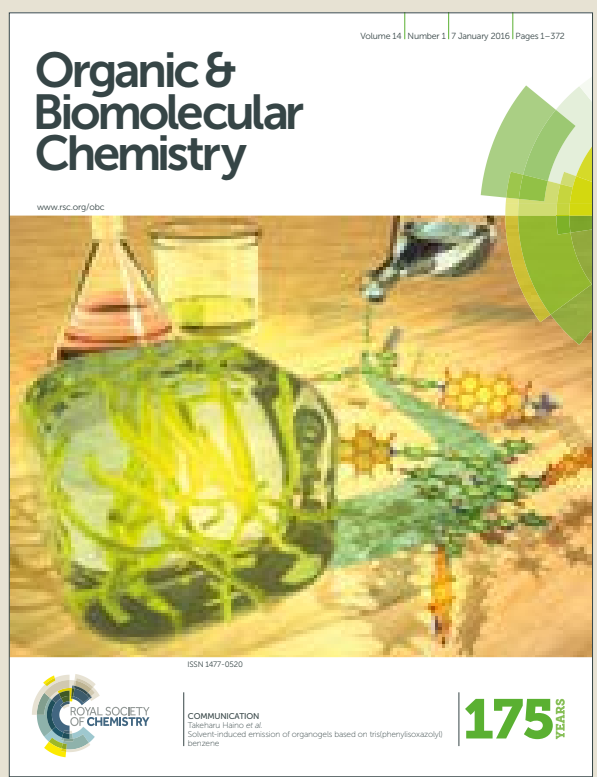

This is an Accepted Manuscript, which has been through the Royal Society of Chemistry peer review process and has been accepted for publication.

Accepted Manuscripts are published online shortly after acceptance, before technical editing, formatting and proof reading. Using this free service, authors can make their results available to the community, in citable form, before we publish the edited article. We will replace this Accepted Manuscript with the edited and formatted Advance Article as soon as it is available.

You can find more information about Accepted Manuscripts in the author guidelines.

Please note that technical editing may introduce minor changes to the text and/or graphics, which may alter content. The journal's standard Terms \& Conditions and the ethical guidelines, outlined in our author and reviewer resource centre, still apply. In no event shall the Royal Society of Chemistry be held responsible for any errors or omissions in this Accepted Manuscript or any consequences arising from the use of any information it contains. 


\title{
Evaluating Aryl Esters as Bench-Stable C(1)-Ammonium Enolate Precursors in Catalytic, Enantioselective Michael Addition- Lactonisations
}

Received 00th January 20xx, Accepted 00th January 20xx

DOI: $10.1039 / \times 0 \times x 00000 x$

www.rsc.org/

\author{
Claire M. Young, James E. Taylor and Andrew D. Smith*
}

\begin{abstract}
An evaluation of a range of aryl, alkyl and vinyl esters as prospective $\mathrm{C}(1)$-ammonium enolate precursors in enantioselective Michael addition-lactonisation processes with $(E)$-trifluoromethylenones using isothiourea catalysis is reported. Electron deficient aryl esters are required for reactivity, with 2,4,6-trichlorophenyl esters providing optimal product yields. Catalyst screening showed that tetramisole was the most effective isothiourea catalyst, giving the desired dihydropyranone product in excellent yield and stereoselectivity (up to 90:10 dr and 98:2 er). The scope and limitations of this process have been evaluated, with a range of diester products being generated after ring-opening with $\mathrm{MeOH}$ to give stereodefined dihydropyranones with excellent stereocontrol (10 examples, typically $\sim 90: 10 \mathrm{dr}$ and $>95: 5 \mathrm{er}$ ).
\end{abstract}

\section{Introduction}

$\mathrm{C}(1)$-Ammonium enolates are valuable reactive intermediates in a variety of diastereo- and enantioselective reactions catalysed by chiral tertiary amine Lewis bases. ${ }^{[1]}$ In early reports, $\mathrm{C}(1)$-ammonium enolates were generated by the interception of an isolated di-substituted ketene or in situ-generated monosubstituted ketene by a tertiary amine catalyst (Fig. 1). ${ }^{[2]}$ More recently, techniques have been developed to generate $C(1)$ ammonium enolates in situ that avoid the use of highly reactive ketenes. These processes rely upon derivatisation of benchstable carboxylic acids to generate reactive acylating agents (such as mixed anhydrides) that readily react with tertiary amine catalysts. Subsequent deprotonation of the resulting $N$ acyl ammonium species generates the desired $C(1)$-ammonium enolate (Fig. 1). Alongside other tertiary amine catalysts, chiral isothioureas have been used extensively as efficient Lewis base catalysts in a range of processes that proceed via an ammonium enolate intermediate. ${ }^{[3,4]}$ For example, a model enantioselective Michael addition-lactonisation process using trifluoromethylenone $\mathbf{1}$ to form stereodefined dihydropyranones $\mathbf{2}$ (Fig. 2a) has been investigated using a range of $C(1)$-ammonium enolate precursors (Fig. 2b). ${ }^{[5,6,7]}$ Carboxylic

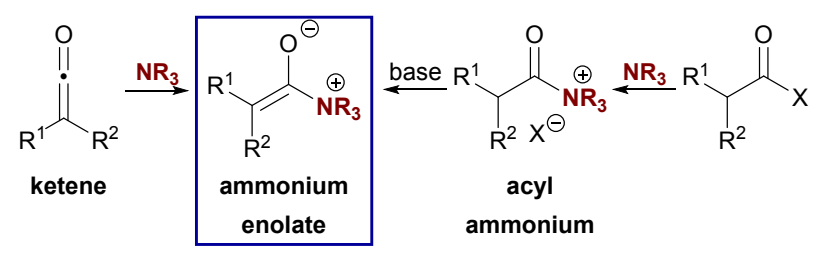

Figure 1: Strategies for ammonium enolate formation

EaStCHEM, School of Chemistry, University of St Andrews, North Haugh, St Andrews, KY16 9ST, UK. E-mail: ads10@st-andrews.ac.uk.

+ Electronic supplementary information (ESI) available: Experimental procedures, product characterisation data (mpt, NMR, IR, HRMS, $\left.[a]_{D}, H P L C\right)$ and traces (NMR, HPLC) can be found at DOI: https://doi.org/10.17630/cb133261-b58e-4d72-b380c877c993dc5d $d^{[23]}$ acids can be derivatised in situ through treatment with pivaloyl chloride (1.5 equiv.) and $i-\mathrm{Pr}_{2} \mathrm{NEt}$ (4 equiv.) to generate a mixed anhydride as an enolate precursor. ${ }^{[5]}$ This protocol generates dihydropyranone $\mathbf{2}$ in good yield and excellent stereoselectivity, however the pivalic anhydride by-product is difficult to separate from the desired product. This approach also relies on using an excess of reagents to facilitate an efficient in situ activation protocol. Bench-stable symmetric carboxylic anhydrides can also be employed as $C(1)$-ammonium enolate precursors. ${ }^{[6]}$ This avoids the requirement for large excesses of additional reagents and minimises side-product formation, although the protocol formally requires two equivalents of the carboxylic acid precursor, which could be a limitation when using complex or expensive acid components. Acyl imidazoles can also be used in isothiourea-catalysed Michael addition-lactonisation reactions, under base-free conditions. ${ }^{[7]}$ However, this process typically requires high catalyst loadings (20 mol\%) and long reaction times to form the dihydropyranone products in slightly reduced yields compared with acid precursors. Notably, the optimal isothiourea catalyst varies with the enolate precursor, with HyperBTM 3 favoured with both carboxylic acids and symmetric anhydrides, while $\mathrm{BTM} \cdot \mathbf{H C l} \mathbf{4} \cdot \mathbf{H C l}$ is optimal when using acyl imidazoles.

Previous mechanistic and computational studies suggest that the nature of the leaving group of the ammonium enolate precursor is not only important for the initial catalyst acylation, but that it is also required for deprotonation of the resulting $N$ acyl ammonium. ${ }^{[5,8]}$ When considering alternative ammonium enolate processes at the carboxylic acid oxidation level it is likely that the leaving group would also need to fulfil this dual requirement. Electron deficient aryl esters are effective acylating agents ${ }^{[9]}$ and have been previously investigated as $\mathrm{C}(1)$-ammonium and -azolium enolate precursors. ${ }^{[10]}$ Within the field of isothiourea catalysis, aryl esters have been used for the formation of $\alpha, \beta$-acyl ammonium intermediates ${ }^{[11]}$ and have found particular utility in processes where the aryloxide leaving 
a) Model Michael-Addition Lactonisation

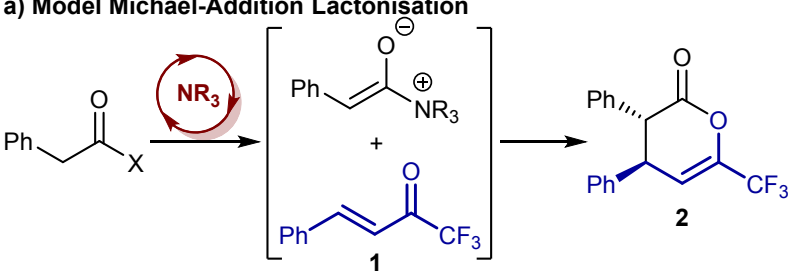

b) Previous $\mathrm{C}(1)$ ammonium enolate precursors

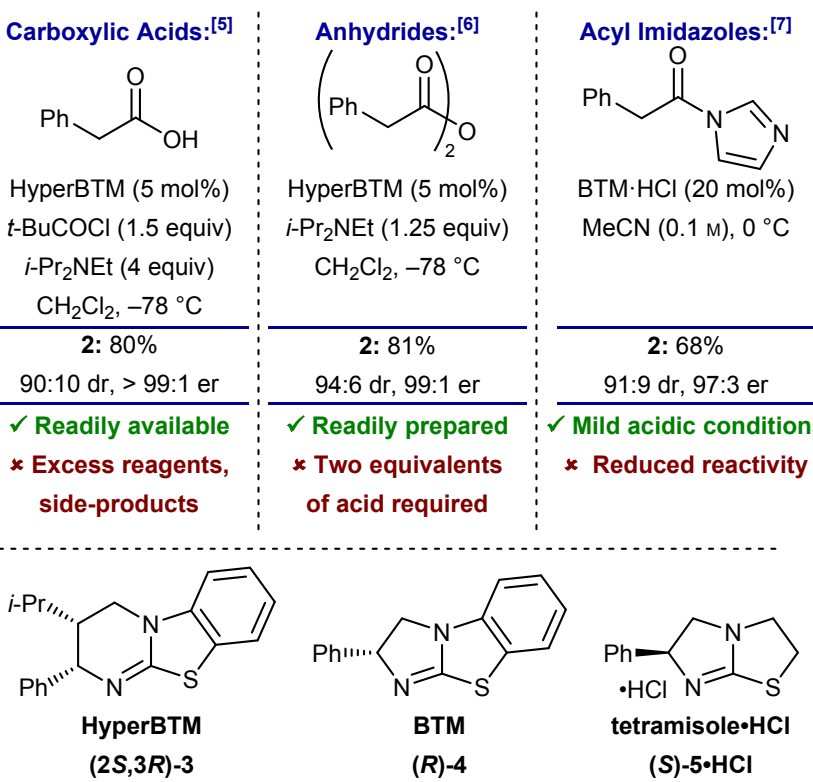

Figure 2: Ammonium enolate precursors in isothiourea-catalysed Michael addition-lactonisation reactions.

group is subsequently required to act as a nucleophile to facilitate catalyst turnover. ${ }^{[12]}$ For example, 4-nitrophenyl esters have been used as substrates in stereoselective [2,3]sigmatropic rearrangements, ${ }^{[13,8 b]}$ as well as enantioselective additions to iminium ions ${ }^{[14]}$ and in $\alpha, \beta$-unsaturated acyl ammonium catalysis. ${ }^{[15]}$ Stable pentafluorophenyl esters have also been used as ammonium enolate precursors in dual catalytic $\alpha$-functionalisation processes developed by the groups of Snaddon, ${ }^{[16]}$ Hartwig ${ }^{[17]}$ and Gong. ${ }^{[18]}$

To date, the use of ester substrates in isothiourea-catalysed formal [4+2] cycloaddition processes proceeding via an ammonium enolate have yet to be explored. In this manuscript, we report the investigation of various bench-stable esters as $\mathrm{C}(1)$-ammonium enolate precursors for Michael addition-

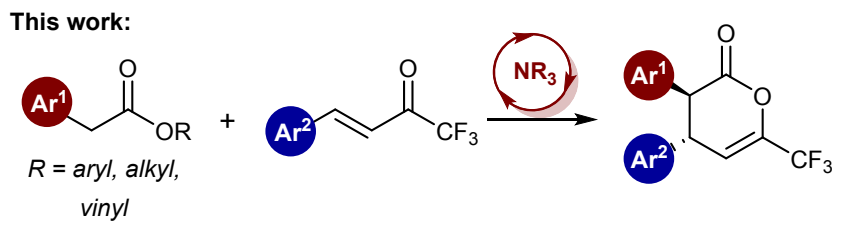

Figure 3: Esters as precursors in isothiourea-catalysed Michael additionlactonisation reactions. lactonisation reactions using trifluoromethylenones as model electrophiles (Fig. 3).

\section{DOI: $10.1039 / \mathrm{C} 90 \mathrm{~B} 00703 \mathrm{~B}$}

\section{Results and discussion}

\section{(i) Screening and Optimisation}

Initially, the isothiourea-catalysed reaction between trifluoromethylenone $\mathbf{1}$ and various potential ammonium enolate precursors to form dihydropyranone $\mathbf{2}$ was studied. To investigate the feasibility of alkyl esters as precursors, trifluoroethyl ester 6 was subjected to representative conditions $\left[(\boldsymbol{S})-\mathbf{5} \cdot \mathbf{H C l}(20 \mathrm{~mol} \%)\right.$ and $i-\operatorname{Pr}_{2}$ NEt ( 2.5 equiv.) in $\mathrm{CH}_{2} \mathrm{Cl}_{2}$ at $\mathrm{rt}$ for $16 \mathrm{~h}$ ]; while vinyl ester 7 was also evaluated due to its known ability to act as an acyl transfer agent. ${ }^{\left[{ }^{9]}\right.}$ Both esters gave $<5 \%$ conversion to product and were not evaluated further (Table 1, Entries 1 and 2). To investigate if an electrondeficient aryl ester was required, a number of electron-deficient aryl $\quad\left(4-\mathrm{NO}_{2} \mathrm{C}_{6} \mathrm{H}_{4}, \quad \mathrm{C}_{6} \mathrm{~F}_{5}, \quad 3,5-\left(\mathrm{CF}_{3}\right)_{2} \mathrm{C}_{6} \mathrm{H}_{3}, \quad 3,4,5-\mathrm{F}_{3} \mathrm{C}_{6} \mathrm{H}_{2}, \quad 2,4,6-\right.$ $\mathrm{Cl}_{3} \mathrm{C}_{6} \mathrm{H}_{2}$ ) phenylacetic ester derivatives 8-12 were prepared from phenylacetyl chloride and the requisite phenol, alongside phenyl ester 13. The aryl esters were then screened in our model reaction (Table 1, Entries 3-8). Electron deficient aryl esters (8-12) gave the desired dihydropyranone in significant yield $(>10 \%$ ) (determined by NMR analysis of the crude material using 1,4-dinitrobenzene as an internal standard) while phenyl ester 13 gave no conversion. ${ }^{[19]}$ Where significant yield was observed, dihydropyranone $\mathbf{2}$ was generally formed in good $\mathrm{dr}$ (> 84:16) and er (> 81:19) (Table 1, Entries 3-7). In particular, trichlorophenyl ester $\mathbf{1 2}$ provided dihydropyranone $\mathbf{2}$ in good $63 \%$ yield along with a promising $84: 16 \mathrm{dr}$ and $87: 13$ er for the major diastereoisomer (Table 1, Entry 7). This suggests that the aryloxide generated following acylation of catalyst by ester $\mathbf{1 2}$ is both a sufficient leaving group for acyl ammonium formation and a suitable base to promote ammonium enolate formation. Notably, trichlorophenyl esters have also previously been found to be optimal for methods in $\alpha, \beta$-unsaturated acyl ammonium catalysis, where the aryloxide is not required to operate as a nucleophile. ${ }^{[11,20]}$

Further optimisation of the reaction with trichlorophenyl ester 12 was then investigated (Table 2). ${ }^{[21]}$ First, the reaction concentration was increased to $0.2 \mathrm{M}$ resulting in a yield of $57 \%$ of $\mathbf{2}$ in $\mathbf{5}$ h at RT with no significant reduction in diastereo- or enantioselectivity (87:13 dr, 88:12 er) (Table 2, Entry 1). In the absence of catalyst, only starting materials were recovered (Table 2, Entry 2). Changing the solvent to THF improved the product er (97:3) while maintaining a good yield (55\%) (Table 2, Entry 3). The use of BTM 4 as catalyst gave comparable results to tetramisole $\cdot \mathbf{H C l} \mathbf{5} \cdot \mathbf{H C l}$ (Table 2, Entry 4), while HyperBTM 3 gave a drop in both yield and enantioselectivity (Table 2, Entry 5). Changing the stoichiometry of auxiliary base and ester to 1 and 2 equivalents respectively and performing the reaction at 0 ${ }^{\circ} \mathrm{C}$ over $16 \mathrm{~h}$, gave dihydropyranone $\mathbf{2}$ with excellent stereoselectivity (89:11 dr, 98:2 er) and in good yield (79\%) as a 
Table 1: Results of acylating agent screen.
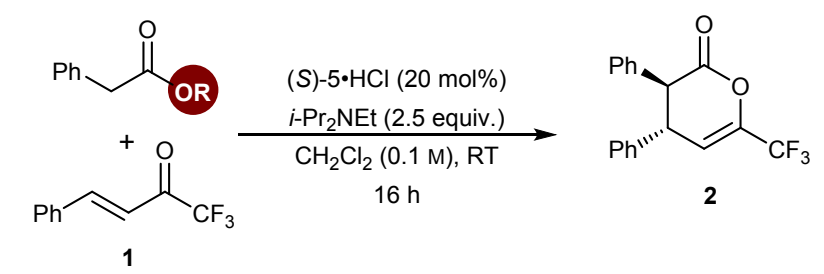

Entry $\mathrm{R}$ Yield (\%) $d r^{b}$ $\mathrm{er}^{\mathrm{c}}$

$\begin{array}{lc}1 & \mathrm{CF}_{3} \mathrm{CH}_{2} \mathbf{6} \\ 2 & \mathrm{CH}_{2}=\mathrm{CH} \mathbf{7} \\ 3 & 4-\mathrm{NO}_{2} \mathrm{C}_{6} \mathrm{H}_{4} \mathbf{8} \\ 4 & \mathrm{C}_{6} \mathrm{~F}_{5} \mathbf{9} \\ 5 & 3,5-\left(\mathrm{CF}_{3}\right)_{2} \mathrm{C}_{6} \mathrm{H}_{3} \mathbf{1 0} \\ 6 & 3,4,5-\mathrm{F}_{3} \mathrm{C}_{6} \mathrm{H}_{2} \mathbf{1 1} \\ 7 & 2,4,6-\mathrm{Cl}_{3} \mathrm{C}_{6} \mathrm{H}_{2} \mathbf{1 2} \\ 8 & \mathrm{C}_{6} \mathrm{H}_{5} \mathbf{1 3}\end{array}$

$<5 \%$
$<5 \%$
32
26
16
11
63
$<5 \%$

$\begin{array}{cc}\mathrm{n} / \mathrm{d} & \mathrm{n} / \mathrm{d} \\ \mathrm{n} / \mathrm{d} & \mathrm{n} / \mathrm{d} \\ 87: 13 & 83: 17 \\ 87: 13 & 85: 15 \\ 88: 12 & 81: 19 \\ 87: 13 & 81: 19 \\ 84: 16 & 87: 13 \\ \mathrm{n} / \mathrm{d} & \mathrm{n} / \mathrm{d}\end{array}$

[a] Yield determined by ${ }^{1} \mathrm{H}$ NMR spectroscopic analysis using $1,4-$ dinitrobenzene as internal standard. [b] Determined by ${ }^{1} \mathrm{H}$ NMR spectroscopic analysis of the crude reaction mixture. [c] $(3 S, 4 S):(3 R, 4 R)$. Determined by chiral HPLC analysis.

mixture of diastereoisomers (Table 2, Entry 6). Under these conditions, the catalyst loading could be reduced to $10 \mathrm{~mol} \%$ without compromising the yield (96\%) or stereoselectivity ( $\mathrm{dr}$ 89:11, er 98:2) (Table 2, Entry 7). This yield and high stereoselectivity compares favourably with those previously reported for other $\mathrm{C}(1)$-ammonium enolate precursors, however, a long reaction time $(48 \mathrm{~h})$ was required. Attempts to lower the catalyst loading to $5 \mathrm{~mol} \%$ compromised the yield in this case (Table 2, Entry 8).

\section{(ii) Scope and Limitations}

Under the optimised conditions, the scope and limitations of the process were explored using various trichlorophenyl arylacetic esters and substituted trifluoromethylenones (Table 3). The crude $d r$ of the reaction products was generally high (around 90:10), while the products were isolated as an inseparable mixture of diastereoisomers. The er of the major diastereoisomer is reported in each case. Incorporation of a strongly electron-withdrawing 4-trifluoromethyl substituent on the arylacetic ester was well tolerated, giving dihydropyranone 14 in good yield (75\%) and 90:10 er (Table 3a). An arylacetic ester bearing an electron-donating 4-methoxy substituent gave $50 \%$ yield of dihydropyranone $\mathbf{1 5}$ in an excellent 95:5 er. The scope was further explored, and the utility of the protocol extended by carrying out in situ methanolysis of the dihydropyranone products by addition of excess methanol after the catalysis. The ring-opened methyl ester products were more stable to column chromatography than the corresponding dihydropyranones, leading to more consistent and representative results (Table $3 b$ ). Keto-ester 16 was isolated as
Table 2: Reaction optimisation.<smiles>CCN(CC)CCCCCC(=O)C(F)(F)C(=O)C=Cc1ccccc1</smiles>

Entry Solvent Temp. Time (h) Catalyst (\%) Yield (\%) $\quad \mathrm{dr}^{\mathrm{a}} \quad \mathrm{er}^{\mathrm{c}}$

$\begin{array}{cccccccc}1 & \mathrm{CH}_{2} \mathrm{Cl}_{2} & \mathrm{RT} & 5 & \mathbf{5} \cdot \mathbf{H C l}(20) & 53 & 87: 13 & 88: 12 \\ 2 & \mathrm{CH}_{2} \mathrm{Cl}_{2} & \mathrm{RT} & 5 & - & 0 & \mathrm{n} / \mathrm{d} & \mathrm{n} / \mathrm{d} \\ 3 & \mathrm{THF} & \mathrm{RT} & 5 & \mathbf{5} \cdot \mathbf{H C l}(20) & 55 & 84: 16 & 97: 3 \\ 4 & \mathrm{THF} & \mathrm{RT} & 5 & \mathbf{4}(20) & 53 & 86: 14 & 4: 96 \\ 5 & \mathrm{THF} & \mathrm{RT} & 5 & \mathbf{3}(20) & 41 & 88: 12 & 10: 90 \\ 6^{\mathrm{d}} & \mathrm{THF} & 0{ }^{\circ} \mathrm{C} & 16 & \mathbf{5} \cdot \mathbf{H C l}(20) & 79 & 89: 11 & 98: 2 \\ 7^{\mathrm{d}} & \mathrm{THF} & 0{ }^{\circ} \mathrm{C} & 48 & \mathbf{5} \cdot \mathbf{H C l}(10) & 96^{\mathrm{e}} & 89: 11 & 98: 2 \\ 8^{\mathrm{d}} & \mathrm{THF} & 0{ }^{\circ} \mathrm{C} & 48 & \mathbf{5} \cdot \mathbf{H C l}(5) & 76^{\mathrm{e}} & 91: 9 & 95: 5\end{array}$

[a] Unless stated, determined by ${ }^{1} \mathrm{H}$ NMR spectroscopic analysis using 1,4dinitrobenzene as internal standard. [b] Determined by ${ }^{1} \mathrm{H}$ NMR spectroscopic analysis of the crude reaction mixture. [c] $(3 S, 4 S):(3 R, 4 R)$. Determined by chiral HPLC analysis. [d] $i-\operatorname{Pr}_{2} \mathrm{NEt}$ (1.0 equiv.), 12 (2.0 equiv.), [e] Isolated yield.

a mixture of diastereoisomers in excellent $86 \%$ yield and 97:3 er after the two-step protocol. Electron-withdrawing arylacetic substituents on the ester were again well tolerated, with ketoesters $\mathbf{1 7}$ (4-trifluoromethyl) and $\mathbf{1 8}$ (4-bromo) isolated in good yields (77\% and $73 \%$ respectively) and enantioselectivity (93:7 and 97:3 er respectively). Electron-donating substituents gave mixed results with 4-methoxy substituted keto-ester 19 isolated in 73\% yield and 97:3 er, while incorporation of a more electrondonating 4-dimethylamino group only gave moderate $51 \%$ yield of $\mathbf{2 0}$ after prolonged reaction time (6 days, some $\mathbf{1}$ remaining) however high er (99:1) was observed. A 2-naphthyl substituent was also tolerated, giving keto-ester $\mathbf{2 1}$ in good $72 \%$ yield and 97:3 er. Variation of the substitution on the aryl group of the enone was then explored (Table 3c). Again, the introduction of electron withdrawing substituents was well tolerated with 4bromo 22 and 3-methoxy 23 substitution giving the corresponding products in good yields $169 \%$ and $86 \%$ respectively) and with high enantioselectivity (95:5 and 94:6 for 22 and 23 respectively). Substitution of the aryl ring with an electron-donating group led to good yield of 4-Me 24 (62\%) with high enantioselectivity (96:4 er). Finally, a heterocyclesubstituted product $\mathbf{2 5}$ was also isolated in good yield (69\%) and excellent 98:2 er albeit it in a lower 71:29 crude dr.

Based upon our previous reports, a mechanism for this process can be postulated. The reaction proceeds through initial acylation of catalyst $\mathbf{5}$ by trichlorophenyl ester $\mathbf{1 2}$ to give acyl ammonium 
Table 3: Substrate screen.

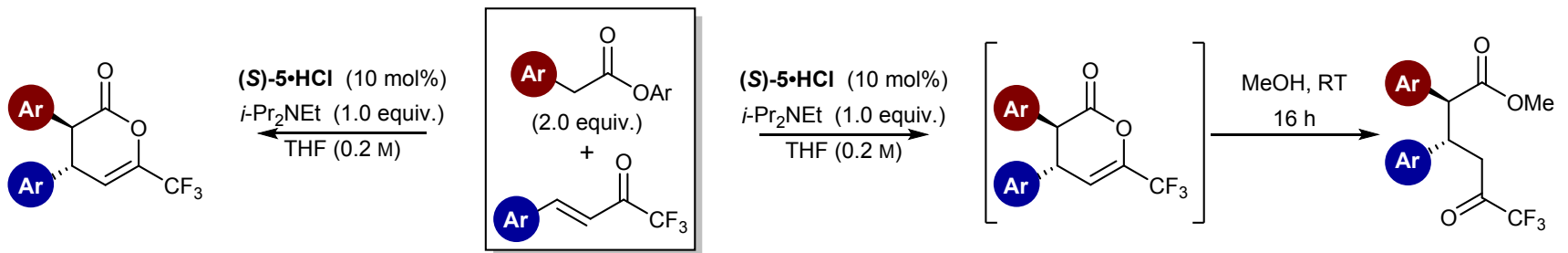

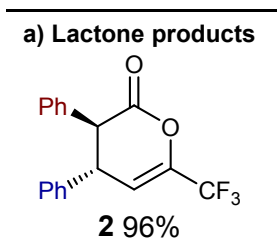

$89: 11 \mathrm{dr}, 98: 2$ er<smiles>O=C1OC(C(F)(F)F)=C[C@H](c2ccccc2)[C@H]1c1ccc(C(F)(F)F)cc1</smiles>

$1475 \%$

$88: 12 \mathrm{dr}, 90: 10 \mathrm{er}$<smiles>COc1ccc(C2C(=O)OC(C(F)(F)F)=C[C@H]2c2ccccc2)cc1</smiles>

$1550 \%$

90:10 dr, 95:5 er<smiles>COC(=O)C(c1ccccc1)[C@H](CC(=O)C(F)(F)F)c1ccccc1</smiles>

$1686 \%$ $88: 12 \mathrm{dr}, 97: 3 \mathrm{er}$<smiles>COC(=O)C(c1ccc(C(F)(F)F)cc1)[C@H](CC(=O)C(F)(F)F)c1ccccc1</smiles>

$1777 \%$

89:11 dr, $93: 7$ er<smiles>COC(=O)C(c1ccc(Br)cc1)[C@H](CC(=O)C(F)(F)F)c1ccccc1</smiles>

$1873 \%$

$83: 17 \mathrm{dr}, 97: 3$ er

c) Ring-opened products: Variation of enone<smiles>COC(=O)[C@H](CC(=O)C(F)(F)F)[C@H](CC(=O)C(F)(F)F)c1cccc(OC)c1</smiles>

$2269 \%$

90:10 dr, 95:5 er
$2386 \%$

90:10 dr, 94:6 er

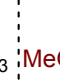<smiles>COC(=O)[C@H](c1ccc2ccccc2c1)[C@H](CC(=O)C(F)(F)F)c1ccc(N(C)C)cc1</smiles>

$1973 \%$

$94: 6 \mathrm{dr}, 97: 3 \mathrm{er}$
$2051 \%$ $\mathrm{dr} n / d,{ }^{[a]} 99: 1$ er
$2172 \%$ 92:8 dr, 97:3 er<smiles>COC(=O)[C@H](c1ccccc1)[C@H](CC(=O)C(F)(F)F)c1ccc(C)cc1</smiles>

$2462 \%$

89:11 dr, 96:4 er<smiles>COC(=O)C(c1ccccc1)[C@H](CC(=O)C(F)(F)F)c1ccco1</smiles>

$2569 \%$

Yields are the isolated yield for a mixture of diastereoisomers after purification. The reported $\mathrm{dr}$ is that of the crude material as determined by ${ }^{1} \mathrm{H}$ NMR spectroscopic analysis. The reported er is given for the major diastereomer $(3 S, 4 S):(3 R, 4 R)$ as determined by chiral $\mathrm{HPLC}$ analysis. [a] dr could not be determined by ${ }^{1} \mathrm{H}$ NMR spectroscopic analysis of the crude material. dr of isolated 19 was 81:18.

ion pair 26. ${ }^{[5]}$ Deprotonation by the aryloxide counter ion then gives the favoured (Z)-ammonium enolate intermediate 27, which exhibits a syn-coplanar geometry due to a stabilising $\mathrm{O} \cdots \mathrm{S}$ interaction. ${ }^{[22]}$ Ammonium enolate $\mathbf{2 7}$ stereoselectively reacts with enone 1 to give intermediate 28. Subsequent cyclisation gives dihydropyranone $\mathbf{2}$ and regenerates catalyst $\mathbf{5}$.

\section{Conclusions}

In conclusion, electron deficient aryl esters are efficient ammonium enolate precursors combining the properties of being competent acylating agents and having a leaving group that is a suitable base for ammonium enolate formation. In a Michael addition-lactonisation with trifluoromethyl enones, trichlorophenyl esters proved to be viable $C(1)$-ammonium enolate precursors giving dihydropyranone products in good to excellent yield and high enantio- and diastereoselectivity. In contrast to other ammonium enolate precursors such as mixed anhydrides, symmetric anhydrides or acyl imidazoles, tetramisole $\mathbf{5} \cdot \mathbf{H C l}$ proved to be the optimal isothiourea catalyst. Subsequent in situ ring opening of dihydropyranones with methanol led to a range of highly functionalised keto-esters in moderate to excellent yield and up to excellent enantio- and diastereoselectivity.

Scheme 1: Proposed catalytic cycle.

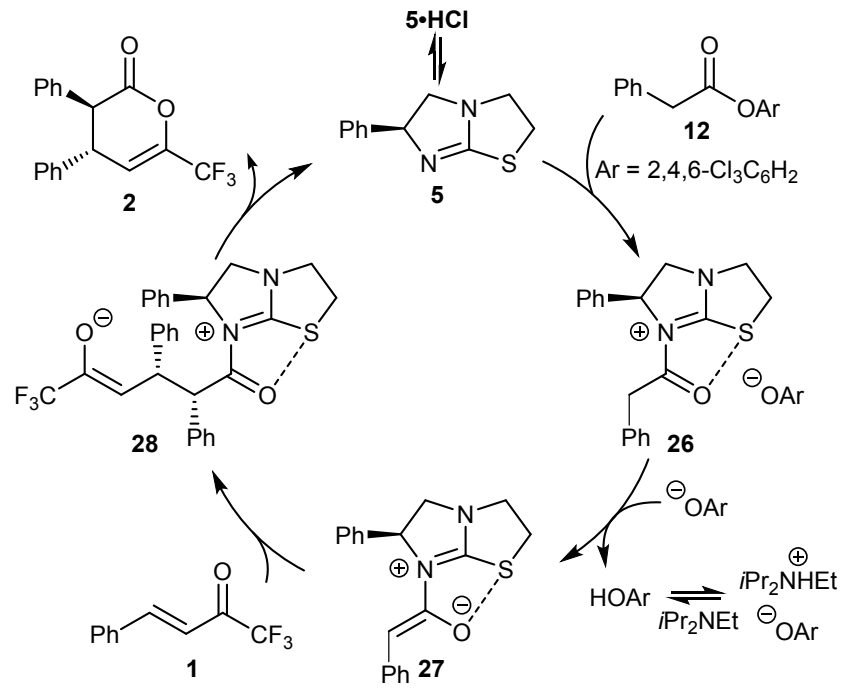




\section{Conflicts of interest}

There are no conflicts to declare.

\section{Acknowledgements}

We thank the European Research Council under the European Union's Seventh Framework Programme (FP7/2007-2013) ERC Grant Agreement no. 279850 (CMY, JET). ADS thanks the Royal Society for a Wolfson Merit Award. We also thank the EPSRC UK National Mass Spectrometry Facility at Swansea University.

\section{Notes and references}

1 For reviews of ammonium enolates see: a) M. J. Gaunt and C. C. C. Johansson, Chem. Rev., 2007, 107, 5596; b) K. N. Van, L. C. Morrill, A. D. Smith and D. Romo in Lewis Base Catalysis in Organic Synthesis, ed.: E. Vedejs and S. E. Denmark, Wiley, Hoboken, vol. 2, ch. 13, pp.527.

2 For selected examples see: a) R. Samtle and H. Pracejus, J. Prakt. Chem., 1972, 314, 157; b) J. C. Sauer, J. Am. Chem. Soc. 1947, 69, 2444; c) H. Wynberg and E. G. J. Staring, J. Am. Chem. Soc., 1982, 104, 166.

3 a) For reviews, see: L. C. Morrill and A. D. Smith, Chem. Soc. Rev., 2014, 43, 6214; b) J. Merad, J.-M. Pons, O. Chuzel and C. Bressy, Eur. J. Org. Chem., 2016, 2016, 5589.

4 For selected examples see: a) V. C. Purohit, A. S. Malta and D. Romo, J. Am. Chem. Soc., 2008, 130, 10478; b) C. A. Leverett V. C. Purohit and D. Romo, Angew. Chem. Int. Ed., 49, 2010, 9479; c) D. Belmessieri, L. C. Morrill, C. Simal, A. M. Z. Slawin and A. D. Smith, J. Am. Chem. Soc., 2011, 133, 2714; d) D. Belmessieri, D. B. Cordes, A. M. Z. Slawin and A. D. Smith, Org. Lett., 2013, 15, 3472; e) S. R. Smith, J. Douglas, H. Prevet, P. Shapland, A. M. Z. Slawin and A. D. Smith, J. Org. Chem., 2014, 79, 1626.

5 L. C. Morrill, J. Douglas, T. Lebl, A. M. Z. Slawin, D. J. Fox and A. D. Smith, Chem. Sci., 2013, 4, 4146.

6 L. C. Morrill, L. A. Ledingham, J.-P. Couturier, J. Bickel, A. D. Harper, C. Fallan and A. D. Smith, Org. Biomol. Chem., 2014, 12, 624.

7 C. M. Young, D. G. Stark, T. H. West, J. E. Taylor and A. D. Smith, Angew. Chem. Int. Ed., 2016, 55, 14394.

8 For selected examples, see: a) K. Nakata, K. Gotoh, K. Ono, K. Futami and I. Shiina, Org. Lett., 2013, 15, 1170; b) T. H. West, D. M. Walden, J. E. Taylor, A. C. Brueckner, R. C. Johnson, P. H.-Y. Cheong, G. C. Lloyd-Jones and A. D. Smith, J. Am. Chem. Soc., 2017, 139, 4366.

9 J. E. Taylor and S. D. Bull, in Comprehensive Organic Synthesis II, ed.: P. Knochel, Elsevier, Amsterdam, 2nd edn, 2014, vol. 6, pp. 427
10 a) L. Hao, X. Chen, S. Chen, K. Jiang, J. Torres and Y. R Chi, Org. Chem. Front., 2014, 1, 148; b) L. Hao, K.dPu, Hoby/, W. cheeno bb Jiang, Y. Shao and Y. R. Chi, Org. Lett., 2012, 14, 2154.

11 A. Matviitsuk, J. E. Taylor, D. B. Cordes, A. M. Z. Slawin and A. D. Smith, Chem. Eur. J., 2016, 22, 17748.

12 For a review see: W. C. Hartley, T. J. C. O'Riordan and A. D. Smith, Synthesis, 2017, 49, 3303.

13 a) T. H. West, D. S. B. Daniels, A. M. Z. Slawin and A. D. Smith, J. Am. Chem. Soc., 2014, 136, 4476; b) T. H. West, S. S. M. Spoehrle and A. D. Smith, Tetrahedron, 2017, 73, 4138; c) S. S. M. Spoerhle, T. H. West, J. E. Taylor, A. M. Z. Slawin and A. D. Smith, J. Am. Chem. Soc., 2017, 139, 11895; d) K. Kasten, A. M. Z. Slawin and A. D. Smith, Org. Lett., 2017, 19, 5182.

14 J. N. Arokianathar, A. B. Frost, A. M. Z. Slawin, D. Stead and A. D. Smith, ACS Catalysis, 2018, 8, 1153.

15 A. Matviitsuk, M. D. Greenhalgh, D. -J. Barrios Antúnez, A. M. Z. Slawin and A. D. Smith, Angew. Chem. Int. Ed., 2017, 56, 12282.

16 a) K. J. Schwarz, J. L. Amos, J. C. Klein, D. T. Do and T. N. Snaddon, J. Am. Chem. Soc., 2016, 138, 5214; b) K. J. Schwarz, C. M. Pearson, G. A. Contron-Rosada, P. Liu and T. N. Snaddon, Angew. Chem. Int. Ed, 2018, 57, 7800; c) K. J. Schwarz, C. Yang, J. W. B. Fyfe and T. N. Snaddon, Angew. Chem. Int. Ed, 2018, 57, 12102; d) L. Hutchings-Goetz, C. Yang and T. N. Snaddon, ACS Catal., 2018, 8, 10537; e) W. R. Scaggs and T. N. Snaddon, Chem. Eur. J. 2018, 24, 14378; f) J. W. B. Fyfe, O. M. Kabia, C. M. Pearson and T. N. Snaddon, Tetrahedron, 2018, 74, 5383; g). W. R. Scaggs, T. D. Scaggs and T. N. Snaddon, Org. Biomol. Chem., 2019, 17, 1787.

17 X. Jiang; J. J. Beiger and J. F. Hartwig, J. Am. Chem. Soc., 2017, 139, 87.

18 Aryl esters have been used in formal [3+2] cycloadditions: J. Song, Z. -J. Zhang, S. -S. Chen, T. Fan and L. -Z. Gong, J. Am. Chem. Soc., 2018, 140, 3177

19 Relative and absolute product configurations assigned by reference to previous work ${ }^{[5]}$

20 M. D. Greenhalgh, S. Qu, A. M. Z. Slawin and A. D. Smith, Chem. Sci., 2018, 9, 4909.

21 For full details see Supporting Information.

22 a) V. I. Minkin and R. M. Minyaev, Chem. Rev. 2001, 101, 1247; b) Y. Nagao, T. Hirata, S Goto, S. Sano and A. Kakehi, J. Am. Chem. Soc., 1998, 120, 3104; c) V. Birman, X. Li and Z. Han Org. Lett., 2007, 9, 37 d) K. A. Brameld, B. Kuhn, D. C. Reuter and M. Stahl, J. Chem. Inf. Model. 2008, 48, 1; e) P. Liu, X. Yang, V. B. Birman and K. N. Houk, Org. Lett. 2012, 14, 3288; f) E. R. T. Robinson, D. M. Walden, C. Fallan, M. D. Geenhalgh, P. H. -Y. Cheong and A. D. Smith, Chem. Sci., 2016, 7, 6919 g) D. J. Pascoe, K. B. Ling and S. L. Cockroft, J. Am. Chem. Soc., 2017, 139, 15160 h) M. D. Greenhalgh, S. M. Smith, D. M. Walden, J. E. Taylor, Z. Brice, E. R. T. Robinson, C. Fallan, D. B. Cordes, A. M. Z. Slawin, H. C. Richardson, M. A. Grove, P. H. -Y. Cheong and A. D. Smith. Angew. Chem. Int. Ed., 2016, 7, 6919

23 The data underpinning this research can be found at DOI: https://doi.org/10.17630/cb133261-b58e-4d72-b380c877c993dc5d 